\title{
Cerebral palsy is prevented if hypoxia index is 24 or less in fetal monitoring
}

\begin{abstract}
Aims: To prevent cerebral palsy, caused by the damage in the birth, using numeric index of fetal heart rate (FHR), that is hypoxia index.

Methods: As fetal outcome was ominous in frequently repeated FHR decelerations, novel hypoxia index (HI) was the sum of durations (min) of FHR deceleration divided by the lowest FHR (bpm) and multiplied by 100 . The index was applied all of eatly, late and variable decelerations as well as continuous fetal bradycardia, where no deceleration pattern was used, but instead FHR score, hypoxia index, frequency spectrum were analyzed.
\end{abstract}

Results: The HI was 25 or more in all of 6 cases, who developed CP, while there was no $\mathrm{CP}$ in all of 16 cases, where HI was 24 or less.

Discussion: Fetal damage and CP was prevented, when $\mathrm{HI}$ is 24 or less, while the $\mathrm{CP}$ developed, if the HI was 25 or more. It is the first study to numerically differentiate normal case from those of $\mathrm{CP}$ production, as all of 16 cases, whose HI was 24 or less, developed no CP, while all 6 cases, whose HI was 25 or more, had CP.. Thus the fetus should receive early delivery when the HI is 24 or less. Thus, intrapartum HI should be 24 or less to prevent $\mathrm{CP}$.

Conclusion: Cerebral palsy will be prevented, if novel hypoxia index is 24 or less in the birth.

Keywords: fetus, heart rate, movement, brain damage, cerebral palsy, hypoxia index, ultrasound, doppler effect
Volume 9 Issue 4 - 2018

\section{Kazuo Maeda}

Obstetrics and Gynecology, Tottori University Medical School, Japan

Correspondence: Kazuo Maeda, MD, PhD, Honorary professor, Obstetrics and Gynecology, Tottori University Medical School, Yonago, 3-125 Nadamachi, Yonago, Tottoriken, 683-0835, Japan, Fax 8I-859-22-6856, Email maedak@mocha.ocn.ne.jp

Received: February 19, 2018 | Published: July 03, 2018
Abbreviations: CP, cerebral palsy; FHR, fetal heart rate; LD, late decelerations; HI, hypoxia index; CTG, cardiotocogram

\section{Introduction}

Although prenatal mortality decreased after the wide use of intrapartum fetal monitoring, infantile cerebral palsy (CP) has not reduced significantly except for some reports in Japan. ${ }^{1,2}$ The author intended to reduce $\mathrm{CP}$ caused by intraartum fetal damage with corect numeric decision.

Although fetal outcome was ominous in a case, whose fetal heart rate (FHR) was late decelerations (LD), which was frequently repeated for 50 minutes, the other neonatal outcome was favorable, of which 1min Apgar score was 9, after three typical connected LDs before caesaran delivery, despite ominous outcome was expected in FHR pattern classification, ${ }^{3}$ where the discrepancy was controversy. In addition, LD was defined after repetition for 15 minutes in some opinion. Thus, LD is ominous, if it repeated frequently, but not due to its particular pattern to delay from uterrine contraction.

\section{Methods}

Thus, a novel Hypoxia Index (HI) to estimate hypoxic effect of FHR decelerations, created by the author, was the sum of FHR deceleration duration (min) divided by the lowest FHR (bpm), and multiplied by 100 to be integer. The index was composed by FHR but not $\mathrm{PaO}_{2}$, because rabbit heart rate is pallarel to $\mathrm{PaO}_{2}$, if $\mathrm{PaO}_{2}$ is lower than $50 \mathrm{mmHg},{ }^{4}$ human fetal $\mathrm{PaO}_{2}$ was 50 or less $\mathrm{mmHg},{ }^{5}$ and intrapartum fetal umbilical cord blood sampling was difficult.
The intrapartum FHR records were studied in 6 babies who were delivered receiving FHR monitoring by the cardiotocogram (CTG), and diagnosed as $\mathrm{CP}$ by pediatric doctor, and 16 normal growth babies also monitored by intrapartum CTG were studied with the novel hypoxia index by the author. The CTGs studied were the records immediately before the deliveries mainly in caesarean delivery (CD) in 6 babies of $\mathrm{CP}$, while the normal babies received $\mathrm{CD}$ due to obstetric indication.

\section{Results}

The hypoxia index was 25 or more in all of 6 cases, who was CP, while hypoxia index of all 16 cases, who had no $\mathrm{CP}$, were 24 or less (Table 1).

Table $1 \chi^{2}$ test of two groups of high and low His

\begin{tabular}{lll}
\hline \multirow{2}{*}{ Hypoxia Index } & \multicolumn{2}{l}{ Cerebral palsy } \\
\cline { 2 - 3 } & Yes & No \\
\hline 25 or more & 6 & 0 \\
24 or less & 0 & 16 \\
\hline
\end{tabular}

$\mathrm{P}=0.000008<0.05$, significant difference, Sensitivity \& Specificity were $100 \%$.

\section{Discussion}

It is recommended to change maternal posture to lateral posture from supine, if fetal LD is detected, because the disappearance of LD was reported after changing maternal posture to lateral one from supine, as the LD was caused by the loss of placental circulation due 
to the pressure of iliac artery by hardly contracted pregnant uterus, which was confirmed by pelvic angiography. ${ }^{6}$ As the loss of FHR variability is the sign of severe fetal brain damage followed by $\mathrm{CP}$, the fetus should be delivered before the loss of variability, actually the HI should be 24 or less. Such numeric threshold has not been reported and the present study is the first numeric recommendation to prevent infantile CP. It was statistically confirmed in Table 1.

Fetal blood $\mathrm{pH}$ was predicted by the deceleration, ${ }^{7}$ and the UApH was also predicted by the high FHR score by the author. ${ }^{8}$ Such studies as deceleration area and hypoxia index will be widely used, instead of FHR pattern classification, in perinatal medicine.

Prospective study will be performed in near future, after completion of a novel FHR analyzing computer, which is composed of FHR score, which predicts Apgar scor and UApH in every 5minutes, hypoxia index and frequency spectrum analysis, which predicts pathologic sinusoidal FHR alarming severe fetal anemia, directly reporting fetal abnormality to attending doctor to rapidly and correctly manage the fetus under the labor.

Novel and early treatment of cerebral palsy will start immediately after the prediction of $\mathrm{CP}$ by the hypoxia index, where the earliest fetal central nervous system change will be detected by magnetic fetal encephalography, which will detect the nervous changes, as well as by ultrasonic imaging of fetal and nenatal brains. Pharmacological therapy, growth factor or stem cell treatments will start immediately after the birth after confirming nervous abnormality using hypoxia index and other update strategies.

Fetal or neonatal brain damage appears not only in the birth, but also in congenital disease, preterm immature babies, TORCHS infection and postpartum events. These damages will be discussed elsewhere.

\section{Conclusion}

Infantile cerebral palsy is predicted and prevented even in the fetus against intrapartum damages by the novel hypoxia index. Other problems were also discussed.

\section{Acknowledgments}

None.

\section{Conflicts of interest}

The author declares that they do not have any conflicts of interest.

\section{References}

1. Tsuzaki T, Sekijima K, Maeda K, et al. The survey on the perinatal variables and the incidence of cerebral palsy for 12 years before and after the application of the fetal monitoring system. Acta Obstet Ginecol jpn. 1990;42:99-105.

2. Takeshita K, Ando Y, Ohtani K, et al. Cerebral palsy in Tottori, Japan. Neuroepidemiology. 1989;8(4):184-92.

3. Hon EH. An Atlas of Fetal Heart Rate Pattern. New Haven: Harty Press. 1968.

4. Umezawa J. Studies on the relation between heart rate and $\mathrm{PaO} 2$ in hypoxic rabbit: a comparative study for fetal heart rate change in labor. Acta Obstet Gynecol Jpn. 1975;28:1203-12.

5. Maeda K, Kimura S, Nakano H, et al. Pathophyaiology of Fetus. Fukuoka: Fukuoka Printing; 1969

6. Poseiro JJ, Mendez-Bauer C, Caldeyro-Barcia R, et al. Effect of uterine contractions on maternal blood flow through the placenta. Paho Advisary Committee. 1969:161-71.

7. Cahill AG, Tuuli MG, Stout MJ, et al. A prospective study of fetal heartrate monitoring; deceleration area is predictive of fetal academia. Am J Obstet Gynecology. 2018;523:1-12.

8. Maeda K. Objective studies on the fetus in the past, present \& future. $E C$ Gynecology. 2018;7(3):86-94. 